\title{
Comparison of exercise capacity in COPD and other etiologies of chronic respiratory failure requiring non-invasive mechanical ventilation at home: retrospective analysis of I-year follow-up
}

\author{
This article was published in the following Dove Press journal: \\ International Journal of COPD \\ 26 November 2015 \\ Number of times this article has been viewed
}

\author{
Cuneyt Salturk' \\ Zuhal Karakurt ${ }^{\prime}$ \\ Huriye Berk Takir' \\ Merih Balci ${ }^{2}$ \\ Feyza Kargin' \\ Ozlem Yazıcıoglu Mocin' \\ Gokay Gungor' \\ Ipek Ozmen' \\ Selahattin Oztas' \\ Murat Yalcinsoy ${ }^{3}$ \\ Ruya Evin' \\ Murat Ozturk' \\ Nalan Adiguzel' \\ 'Respiratory Intensive Care Unit, \\ Sureyyapasa Chest Diseases and \\ Thoracic Surgery Teaching and \\ Research Hospital, ${ }^{2}$ Respiratory \\ Intensive Care Unit, Kartal Kosuyolu \\ Cardiovascular Disease and Surgery \\ Teaching and Research Hospital, \\ Istanbul, ${ }^{3}$ Respiratory Intensive Care \\ Unit, Department of Chest Disease \\ and Pulmonology, Inonu University \\ Medical Faculty, Malatya, Turkey
}

Correspondence: Cuneyt Salturk Respiratory Intensive Care Unit, Sureyyapasa Chest Diseases and Thoracic Surgery Teaching and Research Hospital, Merdivenkoy Mahallesi Ortabahar Sokak, Hakan Apt. No: I5 D: 16 Kadıköy 34732, Istanbul, Turkey

Tel +90505 50l 7242

Email csalturk@yahoo.com
Introduction: The objective of this study was to compare the change in 6-minute walking distance (6MWD) in 1 year as an indicator of exercise capacity among patients undergoing home non-invasive mechanical ventilation (NIMV) due to chronic hypercapnic respiratory failure (CHRF) caused by different etiologies.

Methods: This retrospective cohort study was conducted in a tertiary pulmonary disease hospital in patients who had completed 1-year follow-up under home NIMV because of CHRF with different etiologies (ie, chronic obstructive pulmonary disease [COPD], obesity hypoventilation syndrome [OHS], kyphoscoliosis [KS], and diffuse parenchymal lung disease [DPLD]), between January 2011 and January 2012. The results of arterial blood gas (ABG) analyses and spirometry, and 6MWD measurements with 12-month interval were recorded from the patient files, in addition to demographics, comorbidities, and body mass indices. The groups were compared in terms of 6MWD via analysis of variance (ANOVA) and multiple linear regression (MLR) analysis (independent variables: analysis age, sex, baseline 6MWD, baseline forced expiratory volume in 1 second, and baseline partial carbon dioxide pressure, in reference to COPD group).

Results: A total of 105 patients with a mean age ( \pm standard deviation) of $61 \pm 12$ years of whom 37 had COPD, 34 had OHS, 20 had KS, and 14 had DPLD were included in statistical analysis. There were no significant differences between groups in the baseline and delta values of ABG and spirometry findings. Both univariate ANOVA and MLR showed that the OHS group had the lowest baseline 6MWD and the highest decrease in 1 year (linear regression coefficient -24.48 ; $95 \%$ CI -48.74 to $-0.21, P=0.048$ ); while the $\mathrm{KS}$ group had the best baseline values and the biggest improvement under home NIMV (linear regression coefficient 26.94; $95 \% \mathrm{CI}-3.79$ to $57.66, P=0.085)$.

Conclusion: The 6MWD measurements revealed improvement in exercise capacity test in CHRF patients receiving home NIMV treatment on long-term depends on etiological diagnoses.

Keywords: exercise capacity, non-invasive ventilation, 6-minute walking test, chronic respiratory failure

\section{Introduction}

The availability of non-invasive mechanical ventilation (NIMV) as a treatment choice for chronic hypercapnic respiratory failure (CHRF), and the improved survival in many diseases as a consequence of this treatment, has led to a large increase in the number of patients using home NIMV. ${ }^{1}$ Home NIMV is an effective treatment method for the 
management of CHRF, particularly in patients with chest wall and neuromuscular disorders. ${ }^{2}$ Furthermore, in recent decades, NIMV has been used effectively in the treatment of other diseases that cause CHRF, such as obesity hypoventilation syndrome (OHS) and chronic obstructive pulmonary disease (COPD). ${ }^{3,4}$

The impact of COPD and CHRF on patients' well-being is mainly manifested as a reduction in lung function capacity following daily activities. ${ }^{5}$ Studies have shown discordant results on the benefits of NIMV with respect to quality of life, regardless of the underlying cause of CHRF. ${ }^{6-8}$ Being a cheap, reproducible, and easily standardizable test providing a non-specific, but holistic assessment of exercise capacity, the 6-minute walking test (6MWT) is often used in clinical practice, in addition to the symptom scales and primary pulmonary function tests, such as spirometry and arterial blood gas (ABG) analysis. ${ }^{9}$ The test is well tolerated, cost-effective, and does not require sophisticated equipment to perform. The 6-minute walking distance (6MWD) has been used as an outcome parameter in determining the efficacy of NIMV in both COPD and restrictive diseases. ${ }^{7,10}$ In the present study, we aimed to evaluate exercise capacity among patients with CHRF secondary to COPD and other etiologies, and the impact of NIMV use at home. We used 1-year follow-up data on 6MWT performance relative to the underlying diagnoses.

\section{Methods}

\section{Study population}

A total of 105 consecutive patients with CHRF who received NIMV treatment during their intensive care unit (ICU) hospitalization, and home NIMV post-discharge, were included in this retrospective study conducted from January 2011 to January 2012. Patients who received NIMV in the ICU, or at home for at least 4 hours per day, including nocturnal NIMV, and who attended the first follow-up visit 1 month after discharge and who completed a 1-year post-discharge follow-up at the respiratory intensive care outpatient clinic, were included in the study. These patients had not received NIMV prior to their ICU stay. Patients who were disabled or unwilling to walk, as well as patients with clinical signs of airway infection, current exacerbations, or unstable cardiac arrhythmia, were excluded. A consort diagram showing patient enrollment and study flow is presented in Figure 1.

The ethics committee of Kartal Teaching and Research Hospital, Istanbul, Turkey, approved this study, which was conducted in accordance with the Declaration of Helsinki (No 89513307/1009/427, Date March 26, 2015). It was designed as a retrospective cohort study in a large, pulmonary disease-based, tertiary training and research hospital in Istanbul, Turkey.

\section{Etiologies of CHRF}

Subjects who had no exacerbation episode, nor increased need for ongoing medical treatment and no findings suggestive of acidosis in ABG analysis in 4 weeks prior to the study or measurement were considered to be clinically stable. Subjects in a stable clinical condition were grouped according to their underlying diagnosis as COPD ( $n=37)$, OHS $(n=34)$, kyphoscoliosis (KS, $\mathrm{n}=20$ ), and diffuse parenchymal lung disease (DPLD, $n=14$ ).

The diagnosis of COPD was based on clinical history, symptoms, and airway obstruction (ie, forced expiratory volume in 1 second $\left[\mathrm{FEV}_{1}\right]$ /forced vital capacity [FVC] $<70 \%$ of predicted after bronchodilator inhalation). ${ }^{11} \mathrm{OHS}$ was defined by a body mass index $(\mathrm{BMI})>30 \mathrm{~kg} / \mathrm{m}^{2}$, daytime partial carbon dioxide pressure $\left(\mathrm{PaCO}_{2}\right) \geq 45 \mathrm{mmHg}$ prior to NIMV therapy, and clinical symptoms of CHRF in the absence of other known causes of hypoventilation. ${ }^{12}$ DPLD was defined as lung parenchyma defective due to tuberculosis sequels or bronchiectasis, which caused hypoventilation and resulted in hypoxemia and hypercapnia.

\section{Study procedures}

Demographic data, respiratory symptoms, BMI, and a history of long-term oxygen therapy (LTOT) were recorded retrospectively from our outpatient clinic patient files. Individuals' selfreported comorbidities, as assessed by the Charlson index, ${ }^{13}$ which assigns each disease with a score that is proportional to the disease-related risk of death, were retrieved from the medical files. The Charlson index was computed during the hospital stay by the physician in charge of each admitted patient.

6MWTs were performed twice; once at baseline (1 month after discharge) and once after a 12-month interval, by the same physical therapist. ABG analyses and spirometry performed at the same time points of the 6MWTs were recorded. Data recorded at emergency admission, during the hospital stay and in the interval between the last exacerbation and the 1-year assessment, were evaluated in patients with CHRF relative to their underlying diagnoses. Also, demographic and clinical (baseline and 1-year values for BMI $\left[\mathrm{kg} / \mathrm{m}^{2}\right], \mathrm{FEV}_{1}[\mathrm{~mL}]$, partial carbon dioxide pressure in arterial blood gas analysis $\left[\mathrm{PCO}_{2}\right][\mathrm{mmHg}]$, 6MWD [m], and difference between first and second 6-minute distance with 1-year interval [ $\Delta 6 \mathrm{MWD}]$ ) characteristics of COPD patients were analyzed relative to the presence vs absence of emergency or hospital admission. Pre-test and post-test scores for dyspnea and fatigue at the 1-month and 1-year post-discharge $6 \mathrm{MWT}$ were also evaluated in the study groups. 


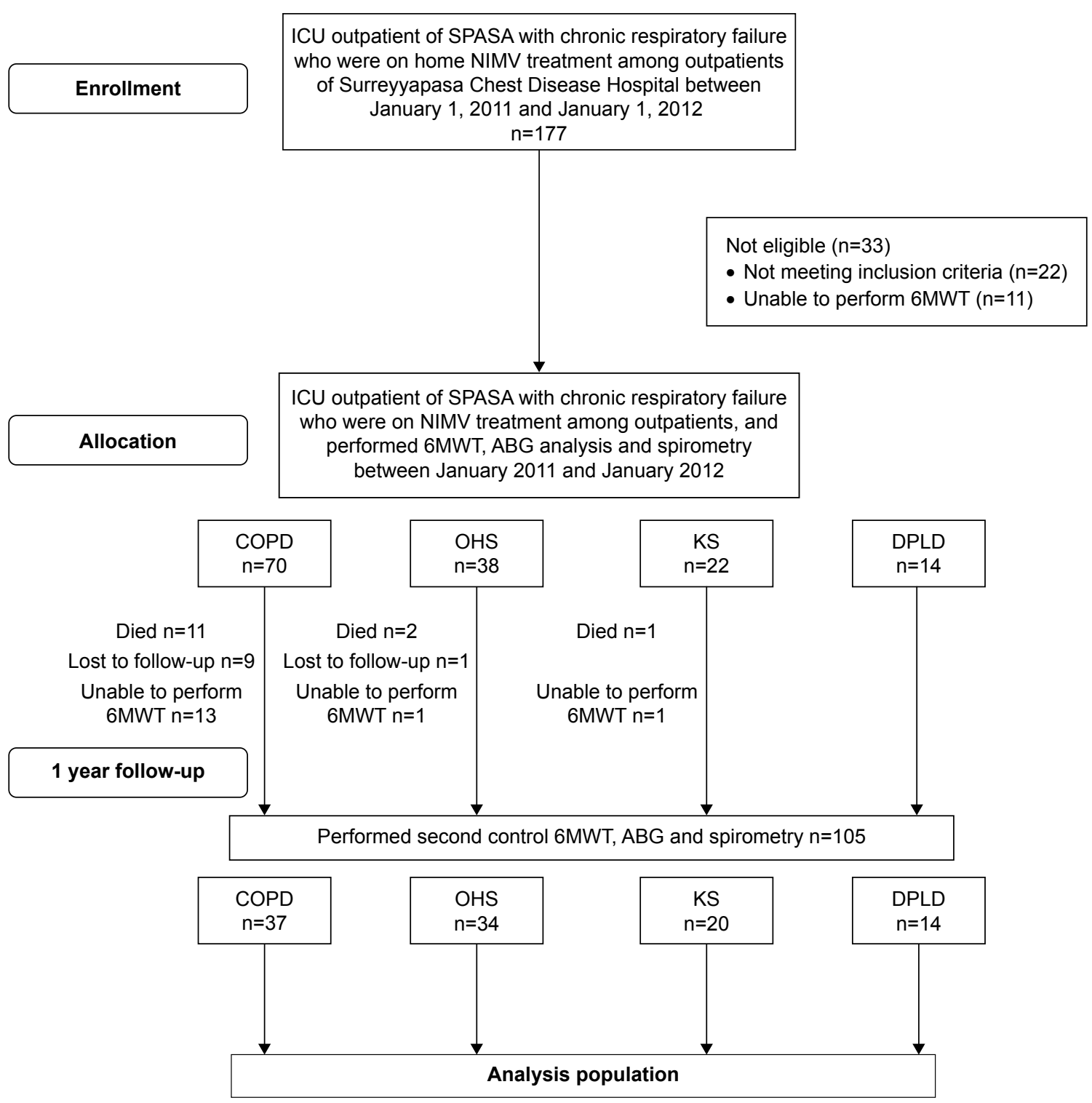

Figure I Consort diagram showing patient enrollment, follow-up and analysis.

Abbreviations: ABG, arterial blood gas analysis; COPD, chronic obstructive pulmonary disease; DPLD, diffuse parenchymal lung disease; ICU, intensive care unit; KS, kyphoscoliosis; NIMV, non-invasive mechanical ventilation; OHS, obesity hypoventilation syndrome; 6MWT, 6-minute walking test; SPASA, Sureyyapasa Chest Disease And Thoracic Surgery Teaching And Research Hospital.

Ideal 6MWT results for all patients were calculated according to the formula described earlier and presented in meters as $6 \mathrm{MWD}$, predicted $6 \mathrm{MWD}$, and predicted percentage 6MWD. Pre- and post-test heart rate, $\mathrm{pH}, \mathrm{PaCO}_{2}$, partial oxygen pressure $\left(\mathrm{PaO}_{2}\right)$, blood bicarbonate $\left(\mathrm{HCO}_{3}\right)$ concentration, $\mathrm{PaO}_{2} /$ fraction of inspired oxygen $\left(\mathrm{FiO}_{2}\right), \mathrm{FEV}_{1}$ ( $\mathrm{mL}$ and \%), FVC ( $\mathrm{mL}$ and \%), and $\mathrm{FEV}_{1} / \mathrm{FVC}$ measurements were also recorded from the medical files. Differences between the results of the two analyses performed 1 year apart for each parameter (delta values) were calculated.

\section{6-Minute walking test}

The 6MWD was determined based on the American Thoracic Society guidelines, while the subjects had their usual oxygen flow. ${ }^{9}$ The test was performed in a $30-\mathrm{m}$ long corridor by a physical therapist with specific experience. Two traffic cones demarcated the course, and the corridor was marked every 3 $\mathrm{m}$. Instructions and verbal encouragement given to the subjects were standardized. Encouragement was given every minute during the test until subject exhaustion. The end of the test was determined, either by the subject for any reason, or by the physical therapist conducting the test. Chest pain, intolerable dyspnea, dizziness, leg cramps, diaphoresis, and pallor were additional criteria for immediately stopping the test. The Borg dyspnea scale ${ }^{14}$ and Visual Analog Scale to Evaluate Fatigue Severity (VAS-F) ${ }^{15}$ were used to determine fatigue and dyspnea scores, respectively, as described. Heart rate was measured before and throughout the 6MWT, with the values recorded at 
the end of each minute during the test. Oxygen saturation was recorded before, and was monitored continuously during the $6 \mathrm{MWT}$, with the tester walking behind the patient. Reference equations, both actual and as a percent-of-predicted 6MWD, are known to be important for assessing cardiopulmonary function. ${ }^{16}$ Ideal 6MWD values were calculated according to a formula, and by using the reference equations provided by Enright and Sherrill. ${ }^{17}$ The test results were recorded as ideal $[1,140-(5.61 \times \mathrm{BMI})-(6.94 \times$ age $)$ for males and $1,017-$ $(6.24 \times \mathrm{BMI})-(5.83 \times$ age $)$ for females], percent-of-predicted (\% of ideal 6MWD), and lower limit of normal values (ideal 6MWD - $153 \mathrm{~m}$ for males and ideal 6MWD - $139 \mathrm{~m}$ for females), according to previous methods.

\section{Home NIMV}

Home NIMV devices were prescribed according to home mechanical ventilation guidelines after a good response was achieved with NIMV during the ICU stay. ${ }^{18}$ All patients had home NIMV via a bi-level positive airway pressure (BiPAP) machine in a spontaneous/timed $(\mathrm{S} / \mathrm{T})$ mode with an oronasal interface. Treatment efficacy was assessed by clinical status and $\mathrm{ABG}$ measurements. Inspiratory positive airway pressure (IPAP) and expiratory positive airway pressure (EPAP) values of NIMV devices were titrated and recorded. A specialized NIMV nurse also measured objective NIMV usage at every outpatient clinic visit by checking the built-in time counter of the NIMV device. The IPAP was titrated during ventilation in steps of $1 \mathrm{mbar} / \mathrm{min}$ to achieve the desired tidal volume, and was set between the EPAP and 30 mbar. Therapy hours of NIMV devices were noted in each control by the same nurse.

\section{BMI calculation}

BMI was calculated and documented. For KS subjects, height was calculated from arm span (largest distance across the middle fingers when the arms were outstretched horizontally). In males, arm span/1.03 m, and in women, arm span/1.01 m, was used for standing height in the regression equation. ${ }^{19}$

\section{ABG analysis}

On the day of the outpatient clinic visit, ABG's (Rapidlab, Bayer, Leverkusen, Germany) were analyzed at rest from the radial artery. Samples were taken in the daytime during spontaneous breathing of room air, if possible, or during the subject's usual oxygen flow. Oxygenation was defined as $\mathrm{PaO}_{2} / \mathrm{FiO}_{2}$. Spirometry (Zan GPI 3.00, nSpire Health, Longmont, CO, USA) was performed according to the American Thoracic Society guidelines. ${ }^{20}$

\section{Statistical analysis}

Data were analyzed using the Statistical Package for Social Sciences, version 15.0 (SPSS 15.0, SPSS, Chicago, IL, USA). The chi-square $\left(\chi^{2}\right)$ test was used for the comparison of categorical data. Numerical data were analyzed using the independent sample $t$-test and one-way analysis of variance (ANOVA) for variables with normal distribution, while the Kruskal-Wallis test was used for non-normal distributed variables. Linear regression analysis, including age, sex, basal measurements of 6MWD, $\mathrm{FEV}_{1}, \mathrm{PaCO}_{2}$, and diagnostic groups, was performed. Data were expressed as the mean \pm standard deviation (SD), percentage (\%), median (percentile 25-75), and 95\% confidence interval (CI, min to max), where appropriate. A $P$-value $<0.05$ was considered significant.

\section{Results}

Among the 105 patients who completed the 1-year follow-up, mean \pm SD age was $61 \pm 12$ years, and $30.5 \%$ were female. Thirty-seven patients had COPD, 34 had OHS, 20 patients had KS, and 14 had DPLD. Baseline characteristics of the study groups are shown in Table 1.

Table I Baseline characteristics of chronic respiratory failure patients having non-invasive ventilation at home followed at the outpatient clinic between $201 \mathrm{I}$ and 2012

\begin{tabular}{|c|c|c|c|c|}
\hline & COPD, $n=37$ & OHS, $n=34$ & Kyphoscoliosis, $\mathbf{n}=\mathbf{2 0}$ & DPLD, $n=14$ \\
\hline Age, years, mean $\pm S D$ & $65 \pm 10$ & $65 \pm 8$ & $46 \pm 10$ & $62 \pm 12$ \\
\hline Female, \% & 8.1 & 50 & 45 & 21.4 \\
\hline $\mathrm{BMI}, \mathrm{kg} / \mathrm{m}^{2}$, mean $\pm \mathrm{SD}$ & $25 \pm 6$ & $4 I \pm 6$ & $27 \pm 7$ & $27 \pm 6$ \\
\hline \multicolumn{5}{|l|}{ HNIV parameters, mean \pm SD } \\
\hline IPAP, $\mathrm{cm} \mathrm{H}_{2} \mathrm{O}$ & $24 \pm 3$ & $23 \pm 3$ & $22 \pm 5$ & $2 I \pm 5$ \\
\hline EPAP, $\mathrm{cm} \mathrm{H}_{2} \mathrm{O}$ & $5.3 \pm 0.7$ & $5.8 \pm 0.8$ & $5.3 \pm 0.6$ & $5.5 \pm 0.7$ \\
\hline Therapy duration, hour/day & $6.7 \pm 1.9$ & $6.4 \pm 2.4$ & $5.9 \pm 1.8$ & $5.8 \pm 1.4$ \\
\hline Charlson comorbidity index, mean \pm SD & $4 \pm 1$ & $4 \pm 1$ & $2 \pm 2$ & $3 \pm 1$ \\
\hline
\end{tabular}

Abbreviations: BMI, body mass index; COPD, chronic obstructive lung disease; DPLD, diffuse parenchymal lung disease; EPAP, expiratory positive airway pressure; HNIV, home non-invasive ventilation; IPAP, inspiratory positive airway pressure; OHS, obesity hypoventilation syndrome; SD, standard deviation. 
The mean \pm SD BMI was $41 \pm 6 \mathrm{~kg} / \mathrm{m}^{2}$ in the OHS group, while it was within normal limits in the other groups (Table 1). All patients had a history of LTOT. Among the comorbidities, arthropathy or joint prostheses that may interfere with the 6MWT were present in only 2 (5.4\%) patients with COPD, $1(5.0 \%)$ patient with KS, 2 (14.3\%) patients with DPLD, and 31 (91.2\%) patients with OHS.

The 6MWD increased in the COPD, KS, and DPLD patients after 1 year, and this was significant in the KS and DPLD groups. It decreased in the OHS group with a change of $-13.9 \mathrm{~m}$ (95\% CI -31.9 to 3.96) (Table 2). The number of patients with a $\triangle 6 \mathrm{MWD} \geq 30 \mathrm{~m}$ was $11(29.7 \%), 8(23.5 \%)$, $12(60.0 \%)$, and $7(50.0 \%)$ in the COPD, OHS, KS, and DPLD patients, respectively.

There were no statistically significant differences between groups in the baseline and delta values of $\mathrm{pH}, \mathrm{PCO}_{2}, \mathrm{PaO}_{2}$, $\mathrm{HCO}_{3}, \mathrm{PaO}_{2} / \mathrm{FiO}_{2}$ ratio, $\mathrm{FEV}_{1}(\mathrm{~mL}), \mathrm{FEV}_{1} \%$, FVC (mL), $\mathrm{FVC} \%$, and $\mathrm{FEV}_{1} / \mathrm{FVC}$ (Table 3).

The baseline and delta values after 1 year of $6 \mathrm{MWD}$ and predicted percentage of 6MWD were significantly different between the four groups, as shown in Table 2 and Figure 2 . The OHS group had the lowest baseline 6MWD, which decreased over time, while the KS group had the best baseline values, and the greatest improvement.

COPD patients had significantly higher post-test scores for dyspnea noted during the 1-year 6MWT compared with patients with other underlying diagnoses [median $3(1-5)$ vs 1 ( $0-2)$ for each other diagnosis, $P=0.003]$. However, no other significant differences were noted between the diagnostic groups in terms of pre- and post-test VAS-F and dyspnea scores during the baseline and 1-year 6MWT (Table 4).

No significant difference was noted in terms of emergency admission, hospital stay, and the interval between the last exacerbation and 1-year assessment in the patients who were clinically stable but with different underlying diagnoses. While OHS patients had significantly higher mean \pm SD values for BMI during the 1-month and 1-year measurements ( $P=0.001$ for each), no significant change was detected in $\triangle \mathrm{BMI}$ from the 1-month to 1-year measurement between the study groups (Table 5).

No significant difference was noted in demographic characteristics as well as mean \pm SD baseline and 1-year values for BMI $\left(\mathrm{kg} / \mathrm{m}^{2}\right), \mathrm{FEV}_{1}(\mathrm{~mL}), \mathrm{PCO}_{2}(\mathrm{mmHg})$, and 6MWD (m) among COPD patients with respect to the presence of emergency or hospital admission (Table 6).

We used linear regression analyses to adjust the change in 6MWD for age, sex, baseline 6MWD, baseline $\mathrm{FEV}_{1}$, and baseline $\mathrm{PaCO}_{2}$ values, and the disease groups were

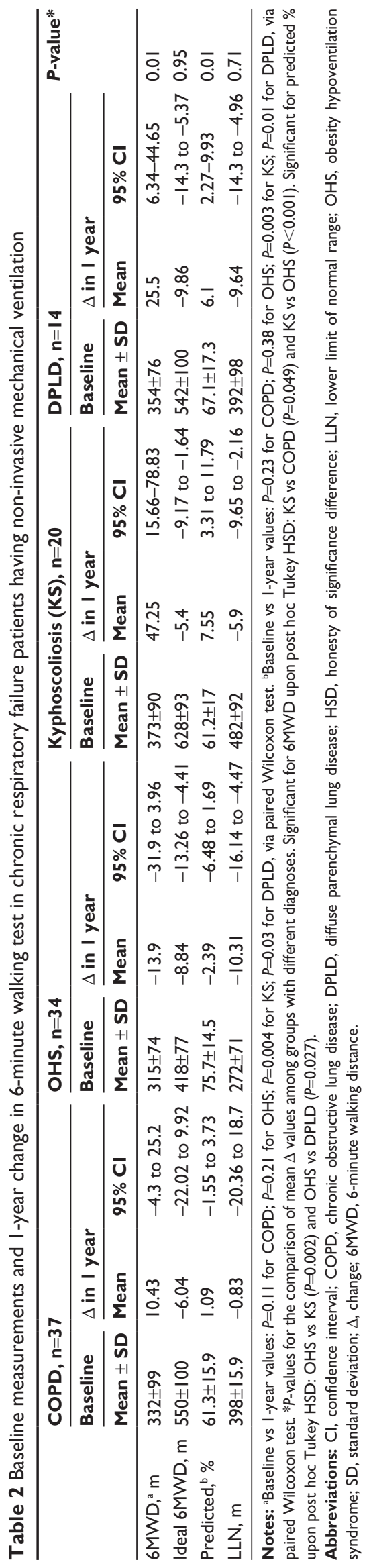




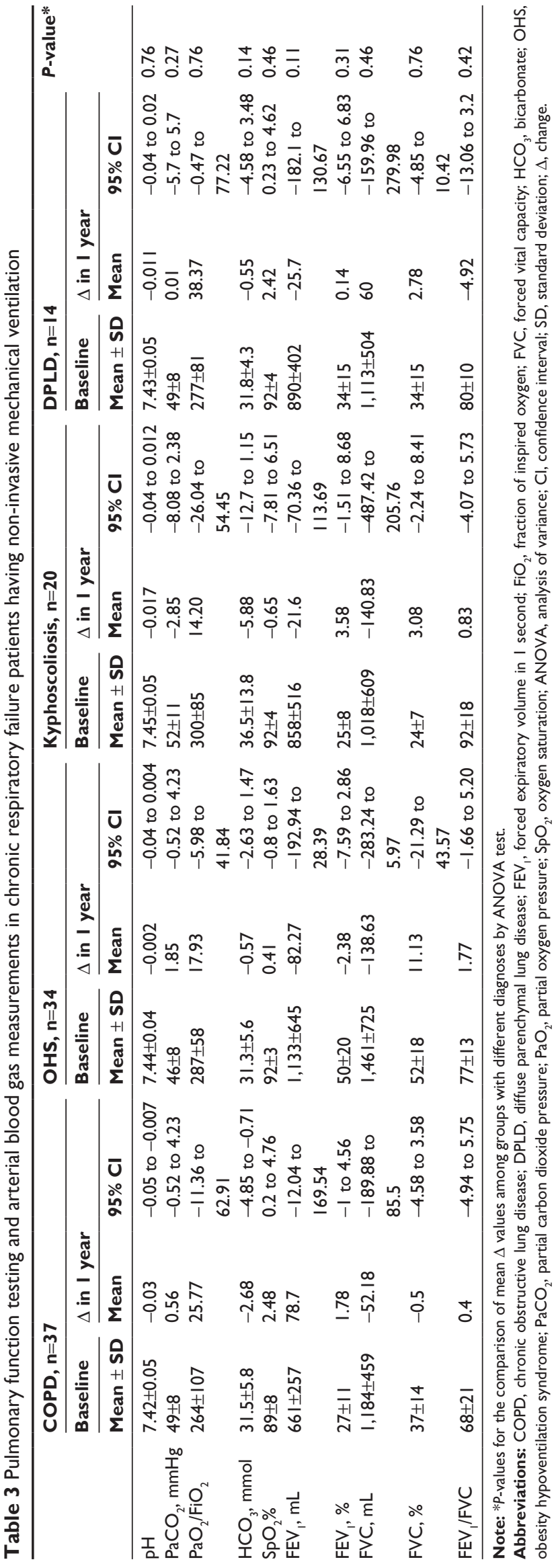

compared with the COPD group (as the reference group). Table 7 shows that OHS is a significant negative predictor factor for an improvement in 6MWD (linear regression coefficient $-24.48 ; P=0.048$ ), indicating that a lower increase in 6MWD is expected in OHS patients compared with COPD patients. Likewise, patients with a higher baseline 6MWD are candidates for a lesser improvement in the distance after 1 year with home NIMV (linear regression coefficient -0.16 ; $P=0.003)$.

\section{Discussion}

The present study showed that after 1 year, exercise capacity, as assessed by a change in the $6 \mathrm{MWD}$, varied according to the etiology of CHRF in patients under home NIMV treatment. We showed a small, non-significant increase in this distance in COPD patients, a significant improvement in KS and DPLD patients, and no improvement, even a worsening (although not significant), in OHS patients.

The efficacy of NIMV treatment for acute respiratory failure due to COPD exacerbation has been well proven. It reduces hospital deaths and complications associated with treatment, and length of hospital stay. ${ }^{21}$ However, studies and systematic reviews on the effects of chronic NIMV in stable hypercapnic COPD are controversial. ${ }^{22}$ Several randomized controlled trials failed to show a clear benefit of home NIMV on lung function, gas exchange, sleep efficiency, and healthrelated outcomes in the treatment of stable COPD. ${ }^{23,24}$ The 6MWT was used as the pulmonary function test to evaluate treatment response in these studies, particularly in those conducted in the 2000s. In a recent randomized study by Funk et al, COPD patients remaining hypercapnic after an acute respiratory failure attack were shown to potentially benefit from long-term NIMV based on improved 6MWD. They also had a higher probability of experiencing clinical deterioration after withdrawal of the NIMV treatment. ${ }^{25}$

Being standardized in terms of disease severity, treatment, and performing the tests, the minimum clinically relevant difference in 6MWD for chronic respiratory diseases has been considered to be $30 \mathrm{~m} .{ }^{26}$ Among our 37 COPD patients only $11(29.7 \%)$ demonstrated this level of 6MWD improvement, which emphasizes the need for larger scale studies for more accurate estimations.

Pinto-Plata et al have investigated the relationship between $\triangle 6 \mathrm{MWD}$ and mortality among severe COPD patients for a minimum of a 1 -year period. ${ }^{27}$ Their prospective study showed that $6 \mathrm{MWD}$ declined progressively over time and it was a better predictor of mortality than $\mathrm{FEV}_{1}, \mathrm{BMI}$, and associated comorbidities. Interestingly, they showed an 


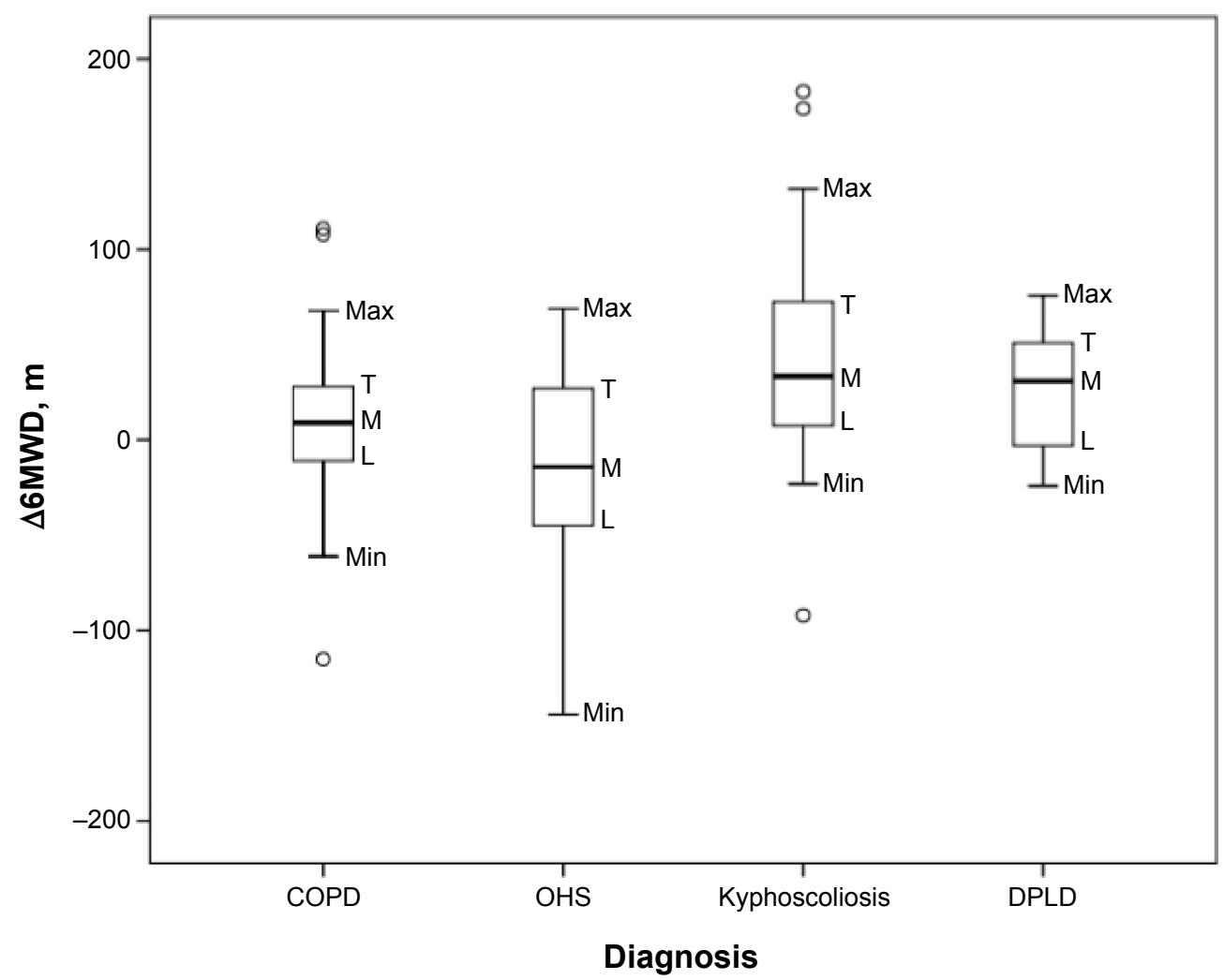

Figure 2 Box plots for delta 6-minute walking test in meters in four diagnosis groups.

Abbreviations: o, outliers; Min, minimum value excluding outliers; Max, maximum value excluding outliers; M, median; T, third quartile; L, first quartile; $\Delta$, change; 6 MWD, 6-minute walking distance; COPD, chronic obstructive lung disease; OHS, obesity hypoventilation syndrome; DPLD, diffuse parenchymal lung disease.

average decline of $26 \mathrm{~m}$ in 1 year, whereas our COPD patients had a mean increase of $10.4 \mathrm{~m}$. Although in the study of Pinto-Plata et al, a history of ICU stay, use of LTOT or home NIMV, ABG analysis, and degree of chronic respiratory failure were not specified, average values reported for basal $\mathrm{FEV}_{1}(1.04 \pm 0.39 \mathrm{~L})$ and $6 \mathrm{MWD}(238 \pm 107 \mathrm{~m})$ were worse than identified in our cohort $(0.66 \pm 0.26 \mathrm{~L}$ and $332 \pm 99 \mathrm{~m}$, respectively). ${ }^{27}$ Therefore, while a more favorable outcome

Table 4 Pre-test and post-test scores for dyspnea and fatigue at baseline and I-year 6MWT in study groups

\begin{tabular}{|c|c|c|c|c|c|}
\hline & COPD, $n=37$ & OHS, $n=34$ & Kyphoscoliosis, n=20 & DPLD, $n=14$ & $P$-value* \\
\hline \multicolumn{6}{|c|}{ Post-discharge 6MWT } \\
\hline \multicolumn{6}{|l|}{ Baseline } \\
\hline \multicolumn{6}{|c|}{ Dyspnea score ${ }^{a}$} \\
\hline Pre-test & $I(I-2)$ & I (0-2) & $0(0-1)$ & $2(0-2)$ & 0.18 \\
\hline Post-test & $2(I-3)$ & $2(0-4)$ & $I(I-3)$ & $2(I-3)$ & 0.67 \\
\hline \multicolumn{6}{|c|}{ VAS-F score ${ }^{a}$} \\
\hline Pre-test & I (0-2) & I (0-2) & $0(0-I)$ & $0(0-2)$ & 0.50 \\
\hline Post-test & $2(0-3)$ & $2(I-3)$ & I $(0-3)$ & I $(0-3)$ & 0.30 \\
\hline \multicolumn{6}{|l|}{ I-year } \\
\hline \multicolumn{6}{|c|}{ Dyspnea score } \\
\hline Pre-test & I $(0-2)$ & I (0-2) & $0(0-1)$ & $I(0-I)$ & 0.80 \\
\hline Post-test & $3(I-5)$ & I (0-2) & I $(0-2)$ & I $(0-2)$ & 0.003 \\
\hline \multicolumn{6}{|l|}{ VAS-F score } \\
\hline Pre-test & $0(0-2)$ & $0(0-2)$ & $0(0-I)$ & $0(0-I)$ & 0.527 \\
\hline Post-test & I (0-3) & I (0-2) & I (0-2) & $\mid(0-\mid)$ & 0.442 \\
\hline
\end{tabular}

Notes: Data are shown as median (25th-75th percentile). ${ }^{\mathrm{a} D y s p n e a}$ and fatigue scores may be between 0 and 10 . Higher scores indicate higher severity. ${ }^{* K r u s k a l-}$ Wallis test.

Abbreviations: COPD, chronic obstructive lung disease; DPLD, diffuse parenchymal lung disease; OHS, obesity hypoventilation syndrome; VAS-F, Visual Analog Scale to Evaluate Fatigue Severity; 6MWT, 6-minute walking test. 
Table 5 Data on body mass index alteration, emergency admission, hospital stay, and the interval between last exacerbation and I-year assessment in study groups

\begin{tabular}{|c|c|c|c|c|c|}
\hline & COPD, $n=37$ & OHS, $n=34$ & Kyphoscoliosis, $n=20$ & DPLD, $n=14$ & $P$-value \\
\hline \multicolumn{6}{|l|}{ Body mass index $\left(\mathrm{kg} / \mathrm{m}^{2}\right)$} \\
\hline Baseline, mean \pm SD & $25.0 \pm 6.0$ & $41.0 \pm 6.0$ & $27.0 \pm 7.0$ & $27.0 \pm 6.0$ & $0.00 \mathrm{I}^{\mathrm{a}}$ \\
\hline I-year, mean \pm SD & $26.0 \pm 6.0$ & $42.0 \pm 6.0$ & $28.0 \pm 7.0$ & $28.0 \pm 6.0$ & $0.00 I^{\mathrm{a}}$ \\
\hline$\Delta$, mean $\pm \mathrm{SD}$ & $0.0 \pm 2.0$ & $0.0 \pm 2.0$ & $0.0 \pm 2.0$ & $1.0 \pm 1.0$ & $0.96^{\mathrm{a}}$ \\
\hline \multicolumn{6}{|l|}{ Emergency admission } \\
\hline Present, n (\%) & $18(17.1)$ & $13(12.4)$ & $5(4.8)$ & $4(3.8)$ & $0.298^{\mathrm{b}}$ \\
\hline Number of admissions, mean $\pm S D$ & $2.0 \pm 1.0$ & $2.0 \pm 1.0$ & $1.0 \pm 0.0$ & $2.0 \pm 1.0$ & $0.312^{\mathrm{a}}$ \\
\hline \multicolumn{6}{|l|}{ Hospital stay } \\
\hline Present, n (\%) & $12(11.4)$ & $4(3.8)$ & $2(1.9)$ & $2(1.9)$ & $0.08 I^{b}$ \\
\hline Number of hospitalizations, mean \pm SD & $2.0 \pm 1.0$ & $2.0 \pm 0.0$ & $1.0 \pm 0.0$ & $2.0 \pm 1.0$ & $0.698^{\mathrm{a}}$ \\
\hline Length of stay (days), mean \pm SD & $10.0 \pm 5.0$ & $11.0 \pm 3.0$ & $7.0 \pm 3.0$ & $10.0 \pm 4.0$ & $0.839^{a}$ \\
\hline Days from last exacerbation to I-year assessment, mean $\pm S D$ & $204.0 \pm 50.0$ & $210.0 \pm 52.0$ & $260.0 \pm 13.0$ & $234.0 \pm 61.0$ & $0.134^{\mathrm{a}}$ \\
\hline
\end{tabular}

Notes: aANOVA test. ${ }^{b} \chi^{2}$ test.

Abbreviations: COPD, chronic obstructive lung disease; DPLD, diffuse parenchymal lung disease; OHS, obesity hypoventilation syndrome; SD, standard deviation; $\triangle$, change; ANOVA, analysis of variance.

Table 6 Demographic and clinical characteristics of patients with COPD according to the presence of emergency or hospital admission

\begin{tabular}{|c|c|c|c|c|c|c|}
\hline & \multicolumn{6}{|c|}{ COPD $(n=37)$} \\
\hline & \multicolumn{3}{|c|}{ Emergency admission } & \multicolumn{3}{|c|}{ Hospital admission } \\
\hline & Present & Absent & $P$-value & Present & Absent & $P$-value \\
\hline Age (years), mean \pm SD & $63 \pm 10$ & $66 \pm 10$ & $0.34^{\mathrm{a}}$ & $66 \pm 8$ & $64 \pm 11$ & $0.53^{\mathrm{a}}$ \\
\hline \multicolumn{7}{|l|}{ Sex, n (\%) } \\
\hline Female & I (5.6) & $2(10.5)$ & & I (8.3) & $2(8)$ & \\
\hline Male & $17(94.4)$ & $17(89.5)$ & & II (9I.7) & $23(92)$ & \\
\hline \multicolumn{7}{|l|}{ BMI $\left(\mathrm{kg} / \mathrm{m}^{2}\right)$, mean $\pm \mathrm{SD}$} \\
\hline Baseline & $23 \pm 6$ & $27 \pm 6$ & $0.048^{a}$ & $24 \pm 4$ & $26 \pm 7$ & $0.30^{\mathrm{a}}$ \\
\hline I-year & $24 \pm 6$ & $28 \pm 6$ & $0.07^{\mathrm{a}}$ & $25 \pm 5$ & $26 \pm 7$ & $0.45^{\mathrm{a}}$ \\
\hline \multicolumn{7}{|l|}{$\mathrm{FEV}_{1}(\mathrm{~mL})$, mean $\pm \mathrm{SD}$} \\
\hline Baseline & $689 \pm 307$ & $633 \pm 202$ & $0.53^{\mathrm{a}}$ & $6 \mid 4 \pm 276$ & $687 \pm 250$ & $0.44^{\mathrm{a}}$ \\
\hline I-year & $785 \pm 302$ & $830 \pm 483$ & $0.74^{\mathrm{a}}$ & $697 \pm 296$ & $864 \pm 432$ & $0.23^{\mathrm{a}}$ \\
\hline \multicolumn{7}{|c|}{$\mathrm{PaCO}_{2}(\mathrm{mmHg})$, mean $\pm \mathrm{SD}$} \\
\hline Baseline & $48 \pm 8$ & $50 \pm 9$ & $0.47^{\mathrm{a}}$ & $48 \pm 8$ & $50 \pm 9$ & $0.58^{\mathrm{a}}$ \\
\hline I-year & $50 \pm 6$ & $50 \pm 9$ & $0.90^{\mathrm{a}}$ & $51 \pm 7$ & $49 \pm 8$ & $0.67^{\mathrm{a}}$ \\
\hline \multicolumn{7}{|l|}{ 6MWD $(m)$, mean $\pm S D$} \\
\hline Baseline & $364 \pm 65$ & $301 \pm 116$ & $0.05^{\mathrm{a}}$ & $359 \pm 51$ & $319 \pm 114$ & $0.25^{\mathrm{a}}$ \\
\hline I-year & $373 \pm 71$ & $314 \pm 108$ & $0.06^{\mathrm{a}}$ & $366 \pm 34$ & $331 \pm 113$ & $0.3 \mathrm{I}^{\mathrm{a}}$ \\
\hline$\triangle 6 M W D$ & $8.56 \pm 50.82$ & $|2.2| \pm 38.58$ & $0.800^{\mathrm{a}}$ & $6.58 \pm 45.25$ & $12.28 \pm 44.74$ & $0.72^{\mathrm{a}}$ \\
\hline
\end{tabular}

Note: andependent sample $t$-test.

Abbreviations: $\mathrm{BMI}$, body mass index; COPD, chronic obstructive lung disease; $\mathrm{FEV}_{1}$, forced expiratory volume in I second; PaCO ${ }_{2}$, partial carbon dioxide pressure; 6MWD, 6-minute walking distance; $\triangle 6 \mathrm{MWD}$, difference between first and second 6-minute distance with I-year interval; SD, standard deviation.

Table 7 Linear regression analysis for $\triangle 6 M W D(\mathrm{~m})$ with adjusted variables and COPD diagnosis as the reference

\begin{tabular}{llll}
\hline Variable & Linear regression coefficient & $\mathbf{9 5 \%} \mathbf{C l}$ & P-value \\
\hline COPD & - & - & - \\
OHS & -24.48 & -48.74 to -0.21 & 0.048 \\
Kyphoscoliosis & 26.94 & -3.79 to 57.66 & 0.09 \\
DPLD & 16.70 & -8.51 to 41.91 & 0.19 \\
Age & -0.80 & -1.69 to 0.08 & 0.07 \\
Male & -4.23 & -25.45 to 17.00 & 0.69 \\
6MWD, m & -0.16 & -0.26 to 0.05 & 0.003 \\
Baseline FEV, $\mathrm{mL}$ & 0.014 & -0.005 to 0.033 & 0.14 \\
PaCO $_{2}$ first, $\mathrm{mmHg}$ & 0.43 & -0.53 to 1.39 & 0.38 \\
\hline
\end{tabular}

Abbreviations: $\mathrm{Cl}$, confidence interval; COPD, chronic obstructive lung disease; DPLD, diffuse parenchymal lung disease; FEV , forced expiratory volume in I second; OHS, obesity hypoventilation syndrome; $\mathrm{PaCO}_{2}$, partial carbon dioxide pressure; $\triangle 6 \mathrm{MWD}$, difference between first and second 6-minute distance with I-year interval; 6MWD, 6-minute walking distance. 
(in terms of 6MWD) identified in our COPD patients may indicate the positive effect of home NIMV on exercise capacity, the likely impact of differences in methodology, disease severity, and patient characteristics on the discrepancy in findings should also be noted.

Nevertheless, given that the four diagnostic groups were homogenous in terms of emergency admission, hospital stay and the interval between the last exacerbation and 1-year assessment, our findings would seem relevant considering the impact of home NIMV on exercise capacity in different etiologies of CHRF in the clinical practice.

In a study by De Backer et al, ${ }^{28} \mathrm{COPD}$ patients remaining chronically hypercapnic after an acute exacerbation were reported to be treated effectively with home NIMV via enabling greater airflow in better functioning parts of the lung with preserved blood flow, which led to better ventilation/ perfusion and improved exercise capacity. This improvement in the distribution of airflow may be affected by the relationship between the level of applied inspiratory pressure and the recruitment of the peripheral airways. In a recent systematic review and individual patient data meta-analysis regarding NIMV in stable COPD, significantly improved gas exchange results were reported to be achieved during the day, and consequently better exercise capacity was associated with an IPAP cut-off point of $18 \mathrm{~cm} \mathrm{H} \mathrm{O}_{2} .{ }^{29}$ Given that no significant difference was noted in demographic characteristics as well as baseline and 1-year values for BMI $\left(\mathrm{kg} / \mathrm{m}^{2}\right), \mathrm{FEV}_{1}(\mathrm{~mL})$, $\mathrm{PCO}_{2}(\mathrm{mmHg})$, and 6MWD $(\mathrm{m})$ among COPD patients with respect to the presence of emergency or hospital admission in our study, the increase in 6MWD of COPD patients in 1 year under home NIMV may be due to the relatively higher IPAP values $\left(24 \mathrm{~cm} \mathrm{H}_{2} \mathrm{O}\right)$.

Home NIMV therapy has been associated with a decline in outpatient admission and hospitalization rates, ${ }^{30}$ as well as better survival with long-term use ${ }^{31}$ in patients with OHS. Also, the addition of long-term NIMV, targeted to greatly reduce hypercapnia, to standard treatment has been shown to be associated with improved survival among patients with hypercapnic stable COPD. ${ }^{32}$

However, there have been limited studies on changes in 6MWD during long-term home NIMV therapy. Castro-Añón et al investigated the impact of home NIMV treatment by assessing 6MWT among 20 patients with OHS. ${ }^{33}$ With a greater mean baseline 6MWD than identified in our cohort $(350 \pm 110 \mathrm{~m})$, the authors reported a significant increase in the distance after 6 months of home NIMV. Interestingly, a decrease in 6MWD was noted in our OHS patients, despite no significant increase in BMI values in 1 year in this group of patients. These contradictory results may be attributed to differences in sample size, disease severity (as revealed by baseline 6MWD), and a history of recent discharge from the ICU, as well as the duration of follow-up. Although CastroAñón et al did not report on the presence of any disabilities or comorbidities, these might have affected 6MWD if present. ${ }^{33}$ The presence of arthropathy or joint prostheses as comorbidities in the majority of our patients with OHS should also be considered when evaluating the lack of improvement in 6MWD. Enright and Sherrill reported that the 6MWT results were affected by the degree of musculoskeletal mobility and aerobic capacity. ${ }^{17}$ Donini et al demonstrated that the presence of a disability, as evaluated by the obesity-related disability test (Test SIO Disabilità Obesità Correlata; TSD-OC), significantly decreased 6MWD. ${ }^{34}$ NIMV treatment improves clinical symptoms, diurnal oxygenation, and respiratory muscle performance in KS patients. ${ }^{35}$ Fuschillo et al conducted a study with six KS patients and showed that a 1-week course of nocturnal NIMV significantly increased 6MWD. ${ }^{36}$ Despite the differences in the sample size (6 vs 20), the duration of follow-up ( 7 days vs 1 year), and the basal 6MWD (244.7 \pm 132.2 vs $373 \mathrm{~m})$, our study also revealed a significant increase in 6MWD in the KS patients $(P=0.004)$. However, this finding proved insignificant in comparison to the mean difference in COPD patients, possibly due to the disparity between the number of subjects in the COPD and KS groups.

The mean $\triangle 6 \mathrm{MWD}$ in the DPLD group did not differ significantly compared to the COPD patients. Home NIMV treatment of patients with tuberculosis sequelae reportedly increases survival with LTOT. ${ }^{37}$ The effect of home NIMV and pulmonary rehabilitation on 6MWT among patients with tuberculosis sequelae was evaluated in two different studies, and it was shown that these patients had the same degree of significant change compared to patients with COPD; consistent with our results. ${ }^{38,39}$ To our knowledge, the only study that compared 6MWD in two different cohorts with different diagnoses, including bronchiectasis and COPD causing CHRF, is the study of Jenkins and Cecins. ${ }^{40}$ In this study, the authors found that the 6MWD of patients with bronchiectasis had a statistically smaller increase compared with COPD patients. However, in addition to the fact that they were not ICU patients, the sample size distribution between the groups was markedly different (COPD, $n=245$; bronchiectasis, $n=33$ ).

There are several limitations that need to be addressed. The most important limitation is the retrospective, nonrandomized design of the study. This makes it difficult to speculate on the specific effects of home NIMV on 6MWD, due to the lack of data on parameters including adherence to home NIMV treatment and level of ventilation control. 
However, it should be noted that considering the large consensus that home NIMV is an effective treatment for CHRF, ethical issues to be raised by constituting a randomized controlled design whereby one of the groups would not receive home NIMV treatment would outweigh its potential research value. Second, we did not have the opportunity to observe the effects of pulmonary rehabilitation, as we did not have a pulmonary rehabilitation center at the time the study was conducted. Third, given that most OHS patients have obstructive sleep apnea that requires frequently elevated EPAP to maintain the patency of upper airway during sleep, lack of data on sleep tests, and thus sleep quality of patients with OHS, seems to be another limitation. These data would extend the knowledge achieved in the current study. Finally, the number of patients recruited in the diagnosis groups may not be sufficient to observe a significant difference between groups. However, there are no studies that we know of that have examined and compared the value of the 6MWT in assessing patients receiving home NIMV for the treatment of chronic respiratory failure due to different etiologies, at the same time and for such a long period.

In conclusion, our data demonstrated that exercise capacity, as measured by the 6MWD, in CHRF patients receiving long-term home NIMV treatment, depends on the etiological diagnosis. The 6MWD stands out as the only parameter that is progressively influenced in the COPD, KS, and DPLD subgroups of CHRF patients receiving home NIMV over a 1-year period. Clinicians should keep in mind that home NIMV therapy may have a favorable effect on exercise capacity in CHRF patients that can be tested with the 6MWT, without any apparent change in spirometry and ABG findings. Although OHS patients showed a decrease in $6 \mathrm{MWD}$, this is thought to be related to their disability and a permanently high BMI, and these patients should be undergoing physical therapy rehabilitation and a strict diet, additional to home NIMV, to increase the benefit of home NIMV.

\section{Acknowledgments}

The authors thank Dr Sharon Forsyth for editing the manuscript. All authors are very thankful for MECOR (Methods in Epidemiologic, Clinical and Operations Research) faculties, particularly Dr Ahmet Ugur Demir.

\section{Disclosure}

The authors report no conflicts of interest in this work.

\section{References}

1. Lloyd-Owen SJ, Donaldson GC, Ambrosino N, et al. Patterns of home mechanical ventilation use in Europe: results from the Eurovent survey. Eur Respir J. 2005;25:1025-1031.

2. Annane D, Orlikowski D, Chevret S. Nocturnal mechanical ventilation for chronic hypoventilation in patients with neuromuscular and chest wall disorders. Cochrane Database Syst Rev. 2014. Doi:10.1002/14651858.CD001941.

3. Ojeda Castillejo E, de Lucas Ramos P, López Martin S, et al. Noninvasive mechanical ventilation in patients with obesity hypoventilationsyndrome. Long-term outcome and prognostic factors. Arch Bronconeumol. 2015;51:61-68.

4. Struik FM, Lacasse Y, Goldstein R, Kerstjens HM, Wijkstra PJ. Nocturnal non-invasive positive pressure ventilation for stable chronic obstructive pulmonary disease. Cochrane Database Syst Rev. 2013;6: CD002878.

5. Saglam M, Vardar-Yagli N, Savci S, et al. Functional capacity, physical activity, and quality of life in hypoxemicpatients with chronic obstructive pulmonary disease. Int J Chron Obstruct Pulmon Dis. 2015;10: 423-428.

6. Perrin C, El Far Y, Vandenbos F, et al. Domiciliary nasal intermittent positive pressure ventilation in severe COPD: effects on lung function and quality of life. Eur Respir J. 1997;10:2835-2839.

7. Nauffal D, Domenech R, Martinez Garcia MA, Compte L, Macian V, Perpina M. Non-invasive positive pressure home ventilation in restrictive disorders: outcome and impact on health-related quality of life. Respir Med. 2002;96:777-783.

8. McEvoy RD, Pierce RJ, Hillman D, et al. Nocturnal non-invasive nasal ventilation in stable hypercapnic COPD: a randomised controlled trial. Thorax. 2009;64:561-566.

9. Holland AE, Spruit MA, Troosters T, et al. An official European Respiratory Society/American Thoracic Society technical standard: field walking tests in chronic respiratory disease. Eur Respir J. 2014;44: $1428-1446$

10. Bourke SC, Tomlinson M, Williams TL, Bullock RE, Shaw PJ, Gibson GJ. Effects of non-invasive ventilation on survival and quality of life in patients with amyotrophic lateral sclerosis: a randomised controlled trial. Lancet Neurol. 2006;5:140-147.

11. Global initiative for chronic Obstructive Lung Disease. Global strategy for the diagnosis, management, and prevention of chronic obstructive pulmonary disease. Update2011. Available from: http://www.goldcopd. org. Accessed March 1, 2013.

12. Olson $\mathrm{AL}$, Zwillich $\mathrm{C}$. The obesity hypoventilation syndrome. Am J Med. 2005;118:948-956.

13. Charlson ME, Pompei P, Ales KL, MacKenzie CR. A new method of classifying prognostic comorbidity in longitudinal studies: development and validation. J Chronic Dis. 1987;40:373-383.

14. Borg GA. Psychophysical bases of perceived exertion. Med Sci Sports Exerc. 1982;14:377-381.

15. Lee KA, Hicks G, Nino-Murcia G. Validity and reliability of a scale to assess fatigue. Psychiatry Res. 1991;36:291-298.

16. Güngör G, Karakurt Z, Adigüzel N, et al. The 6-minute walk test in chronic respiratory failure: does observed or predicted walk distance better reflect patient functional status? Respir Care. 2013;58: $850-857$.

17. Enright PL, Sherrill DL. Reference equations for the six-minute walk in healthy adults. Am J Respir Crit Care Med. 1998;158: 1384-1387.

18. Clinical indications for noninvasive positive pressure ventilation in chronic respiratory failure due to restrictive lung disease, $\mathrm{COPD}$, and nocturnal hypoventilation - a consensus conference report. Chest. 1999;116: 521-534.

19. Parker JM, Dillard TA, Phillips YY. Arm span-height relationships in patients referred for spirometry. Am J Respir Crit Care Med. 1996; 154:533-536. 
20. Miller MR, Hankinson J, Brusasco V, et al. ATS/ERS task force: standardisation of lung function testing standardization of spirometry. Eur Respir J. 2005;26:319-338.

21. Ram FS, Picot J, Lightowler J, Wedzicha JA. Non-invasive positive pressure ventilation for treatment of respiratory failure due to exacerbations of chronic obstructive pulmonary disease. Cochrane Database Syst Rev. 2004;(3):CD004104.

22. Systematic review of noninvasive positive pressure ventilation in severe stable COPD. Eur Respir J. 2007;30:293-306.

23. Struik FM, Sprooten RT, Kerstjens HA, et al. Nocturnal non-invasive ventilation in COPD patients with prolonged hypercapnia after ventilatory support for acute respiratory failure: a randomised, controlled, parallel-group study. Thorax. 2014;69:826-834.

24. Casanova C, Celli BR, Tost L, et al. Long-term controlled trial of nocturnal nasal positive pressure ventilation in patients with severe COPD. Chest. 2000;118:1582-1590.

25. Funk GC, Breyer MK, Burghuber OC, et al. Long-term non-invasive ventilation in COPD after acute-on-chronic respiratory failure. Respir Med. 2011;105:427-434.

26. Field exercise tests in diagnosis, prognosis and treatment: an update from the ATS/ERS Task Force on Field Exercise Tests. In: ERS 24th Annual Congress; September 6-10, 2014; Munich, Germany.

27. Pinto-Plata VM, Cote C, Cabral H, Taylor J, Celli BR. The 6-min walk distance: change over time and value as a predictor of survival in severe COPD. Eur Respir J. 2004;23:28-33.

28. De Backer L, Vos W, Dieriks B, et al. The effects of long-term noninvasive ventilation in hypercapnic COPD patients: a randomized controlled pilot study. Int J Chron Obstruct Pulmon Dis. 2011;6:615-624.

29. Struik FM, Lacasse Y, Goldstein RS, Kerstjens HA, Wijkstra PJ. Nocturnal noninvasive positive pressure ventilation in stable COPD: a systematic review and individual patient data meta-analysis. Respir Med. 2014;108:329-337.

30. Berg G, Delaive K, Manfreda J, Walld R, Kryger MH. The use of health-care resources in obesity-hypoventilation syndrome. Chest. 2001 120:377-383.
31. Pérez de Llano LA, Golpe R, Ortiz Piquer M, et al. Short-term and longterm effects of nasal intermittent positive pressure ventilation in patients with obesity-hypoventilation syndrome. Chest. 2005;128:587-594.

32. Köhnlein T, Windisch W, Köhler D, et al. Non-invasive positive pressure ventilation for the treatment of severe stable chronic obstructive pulmonary disease: a prospective, multicentre, randomised, controlled clinical trial. Lancet Respir Med. 2014;2:698-705.

33. Castro-Añón O, Golpe R, Pérez-de-Llano LA, et al. Haemodynamic effects of non-invasive ventilation in patients with obesityhypoventilation syndrome. Respirology. 2012;17:1269-1274.

34. Donini LM, Poggiogalle E, Mosca V, Pinto A, Brunani A, Capodaglio P. Disability affects the 6-minute walking distance in obese subjects (BMI>40 kg/m(2)). PLoS One. 2013;11:8(10):e75491.

35. Gonzalez C, Ferris G, Diaz J, Fontana I, Nuñez J, Marín J. Kyphoscoliotic ventilatory insufficiency: effects of long-term intermittent positive-pressure ventilation. Chest. 2003;124:857-862.

36. Fuschillo S, De Felice A, Gaudiosi C, Balzano G. Nocturnal mechanical ventilation improves exercise capacity in kyphoscoliotic patients with respiratory impairment. Monaldi Arch Chest Dis. 2003;59:281-286.

37. Jäger L, Franklin KA, Midgren B, Löfdahl K, Ström K. Increased survival with mechanical ventilation in posttuberculosis patients with the combination of respiratory failure and chest wall deformity. Chest. 2008;133:156-160.

38. Ando M, Mori A, Esaki H, et al. The effect of pulmonary rehabilitation in patients with post-tuberculosis lung disorder. Chest. 2003;123: 1988-1995.

39. Schönhofer B, Zimmermann C, Abramek P, Suchi S, Köhler D, Polkey MI Non-invasive mechanical ventilation improves walking distance but not quadriceps strength in chronic respiratory failure. Respir Med. 2003; 97:818-824.

40. Jenkins S, Cecins NM. Six-minute walk test in pulmonary rehabilitation: do all patients need a practice test? Respirology. 2010;15(8): 1192-1196.
International Journal of COPD

\section{Publish your work in this journal}

The International Journal of COPD is an international, peer-reviewed journal of therapeutics and pharmacology focusing on concise rapid reporting of clinical studies and reviews in COPD. Special focus is given to the pathophysiological processes underlying the disease, intervention programs, patient focused education, and self management protocols.

\section{Dovepress}

This journal is indexed on PubMed Central, MedLine and CAS. The manuscript management system is completely online and includes a very quick and fair peer-review system, which is all easy to use. Visit http://www.dovepress.com/testimonials.php to read real quotes from published authors. 